\title{
OUTBREAK OF PANTOEA SPECIES IN A TERTIARY CARE CHILDREN'S HOSPITAL IN NORTH INDIA- A CASE SERIES
}

\author{
Shivani Tyagi1, Satinder Aneja2 ${ }^{2}$, V. S Randhawa ${ }^{3}$, Abhijeet Saha ${ }^{4}$, Ravinder Kaur ${ }^{5}$ \\ ${ }^{1}$ Senior Resident, Department of Microbiology, Lady Hardinge Medical College \& Associated Hospitals, New Delhi. \\ 2Director Professor, Department of Paediatrics, Lady Hardinge Medical College \& Kalawati Saran Children Hospital, New Delhi. \\ ${ }^{3}$ Director Professor, Department of Microbiology, Lady Hardinge Medical College \& Associated hospitals, New Delhi. \\ ${ }^{4}$ Professor, Department of Paediatrics, Lady Hardinge Medical College \& Kalawati Saran Children Hospital, New Delhi. \\ ${ }_{5}^{5}$ irector Professor and HOD, Department of Microbiology, Lady Hardinge Medical College \& Associated Hospitals, New Delhi.
}

\section{ABSTRACT}

\section{BACKGROUND}

Pantoea genus comprises bacteria that are primarily opportunistic pathogens, but rarely cause disease in healthy individuals.

\section{MATERIALS AND METHODS}

An outbreak of sepsis caused by Pantoea spp. in a high dependency unit of a paediatric tertiary care hospital is presented in this report. Six cases developed nosocomial sepsis over a period of 20 days during October 2016. Blood culture samples sent to microbiology laboratory, processed in automated BacT/Alert blood culture system grew Pantoea spp.

\section{RESULTS}

Blood samples of all the six cases that developed sepsis within a span of 20 days in the same paediatric unit grew the same bacteria; Pantoea spp. with the same antibiotic susceptibility pattern.

\section{CONCLUSION}

Clustering of cases over a short period, points towards the ability of Pantoea spp. to cause outbreak. Reporting of Pantoea spp. should not be ignored when isolated from clinical samples. Possible exogenous sources for this organism should be monitored in a hospital setting.

\section{KEYWORDS}

Pantoea, Sepsis, Outbreak.

HOW TO CITE THIS ARTICLE: Tyagi S, Aneja S, Randhawa VS, et al. Outbreak of Pantoea species in a tertiary care children's hospital in North India- A case series. J. Evolution Med. Dent. Sci. 2017;6(47):3664-3667, DOI: 10.14260/Jemds/2017/790

\begin{abstract}
CASE SERIES
In 1989, genus Pantoea was newly created which included the former species of Enterobacter and Erwinia. Pantoea agglomerans is the type species. 'Pantoea', a Greek word means "of all sorts and sources", is described as bacteria coming from diverse geographic and ecologic sources. ${ }^{1}$ Bacteria belonging to Pantoea genus are primarily opportunistic pathogens but rarely cause disease in healthy individuals. $^{2}$ Septic arthritis, synovitis, cholelithiasis, occupational respiratory infections, skin allergy, peritonitis and blood stream infection are the most common infections caused by it. ${ }^{3}$ Here we report an outbreak caused by Pantoea spp. in a high dependency unit of a paediatric tertiary care hospital in Northern India.
\end{abstract}

\section{Case Presentation 1}

A one-month-old male baby presented to hospital with a history of not passing urine for 2 days, high grade fever for 3

Financial or Other, Competing Interest: None.

Submission 08-05-2017, Peer Review 01-06-2017,

Acceptance 07-06-2017, Published 12-06-2017.

Corresponding Author:

Dr. Shivani Tyagi,

Senior Resident,

Department of Microbiology,

Lady Hardinge Medical College \& Associated

Hospitals, New Delhi-110001, India.

E-mail:dr_shivani_tyagi@yahoo.com

DOI: $10.14260 /$ jemds $/ 2017 / 790$ days and a seizure like episode. On examination, general condition of the child was very sick, heart rate 144/minute; respiratory rate $64 /$ minute with bilateral crepitations, abdominal distension and hepatosplenomegaly. Investigations sent on the day of admission (Table 1), revealed deranged renal function tests but CSF examination and liver function tests were normal and blood culture was sterile. The baby was started on intravenous fluid, injection Cefotaxime and Vancomycin and inotropes were added in view of septic shock. Over next 11 days, despite vigorous management, his general condition did not improve. Patient was in severe sepsis with pneumonia, acute kidney injury and septic ileus with worsening anaemia (haemoglobin $6.9 \mathrm{~g}$ ) and thrombocytopenia $(66000 / \mu \mathrm{L})$. Blood culture sent on day 6 was flagged positive which was processed by automated BacT/Alert blood culture system. The organism isolated from the sample showed following characteristics: On blood agar, the colonies were yellow pigmented, moist, and convex whereas on MacConkey's agar the isolate was a non-lactose fermenter. Gram staining showed Gram-negative bacilli. Biochemically, the isolate was catalase positive, oxidase negative and was further identified by Vitek ID system as Pantoea spp. The organism was susceptible to Ceftazidime $(0.25 \mu \mathrm{g} / \mathrm{mL})$, Piperacillin + Tazobactam $(\leq 4 \mu \mathrm{g} / \mathrm{mL})$ Imipenem $(\leq 0.25 \mu \mathrm{g} / \mathrm{mL})$, Meropenem $(\leq 0.25 \mu \mathrm{g} / \mathrm{mL})$, Ciprofloxacin $(\leq 0.25 \mu \mathrm{g} / \mathrm{mL})$, Gentamicin $(\leq 1 \mu \mathrm{g} / \mathrm{mL})$, Amikacin $(\leq 2 \mu \mathrm{g} / \mathrm{mL})$, Trimethoprim + sulfamethoxazole $(\leq 20 \mu \mathrm{g} / \mathrm{mL})$, Colistin $(\leq 0.5 \mu \mathrm{g} / \mathrm{mL})$ and Tigecycline $(\leq 0.05$ 
$\mu \mathrm{g} / \mathrm{mL}$ ) by Vitek ST System. Patient's antibiotics were upgraded to Piperacillin + tazobactam initially and to Meropenem later on. The child received packed red blood cell transfusion and platelets transfusion. Injection Amphotericin $B$ was added in view of persistent thrombocytopenia. But the patient deteriorated further, went into multiorgan failure and expired due to underlying disease.

\section{Case Presentation 2}

A 7-year-old male child presented to hospital with acute febrile illness, swelling over both knees, pain in abdomen and fast breathing. General condition of the child was very poor. The child was started on intravenous fluids, injection Ceftriaxone and Vancomycin. Initial investigations are mentioned in table 1. Ultrasound of leg showed bilateral leg pyomyositis. The patient also had renal failure. Blood culture sent on $3^{\text {rd }}$ day of admission yielded Pantoea spp. with same antibiotic susceptibility profile as in the first case. The antibiotics were changed to injection Piperacillin + Tazobactam and Doxycycline. Peritoneal dialysis was done in view of persistent metabolic acidosis. Multiple packed red blood cells were transfused. But the child's condition deteriorated as he developed multiorgan dysfunction syndrome (stage 3) with uremic encephalopathy, hyperkalaemia, disseminated intravascular coagulation and shock. Despite aggressive management, the patient expired on $4^{\text {th }}$ day of hospitalisation.

\section{Case Presentation 3}

A 1-day-old male baby who was born at post term (Mother had prolonged leak per vagina for $>48$ hours) by caesarean section with macrosomia and meconium aspiration at a private hospital. The child when brought to our centre was in severe respiratory distress and had developed hypoglycaemia. General condition of the child was very sick with weak respiratory efforts; $\mathrm{SpO} 2$ was $82 \%$ on oxygen by nasal cannula. His investigation profile is mentioned in Table 1. He was intubated and mechanically ventilated and started on intravenous fluids, injection Cefotaxime, and Amikacin but the hypoglycaemia and respiratory distress still persisted. Blood culture was sent on $2^{\text {nd }}$ day of admission which yielded the same organism with same antibiotic susceptibility profile as in the first case. On $3^{\text {rd }}$ day, child condition deteriorated and succumbed to death.

\section{Case Presentation 4}

A 6-day-old female child born at term by normal vaginal delivery on $6^{\text {th }}$ day presented to hospital with icterus for 2 days. Systemic examination findings were insignificant and investigation results are given in Table 1 . She was given phototherapy in view of hyperbilirubinaemia. On $3^{\text {rd }}$ day on admission, the child deteriorated with fever spikes, lethargy and refusal to feeds, oxygen saturation decreased to $84-86 \%$ on room air. She was started on intravenous fluid, injection Cefotaxime and Amikacin. Later during the day, child's condition worsened further with septic shock and respiratory distress. Blood culture sent on the $3^{\text {rd }}$ day grew Pantoea spp. with similar susceptibility profile as in other cases. In view of this, antibiotics were upgraded to Meropenem. Child was electively intubated and mechanically ventilated and fresh frozen plasma was also infused to correct thrombocytopenia but the child expired.

\section{Case Presentation 5}

A 1-1/2-year-old male child having developmental delay presented to hospital with history of fever for 12 days, cough for 10 days, loose stools for 6 days, haematemesis for 6 days and decreased urine output for 3 days. Patient was admitted for 3 days at a private hospital for the above complaints and had severe anaemia, thrombocytopenia, dyselectrolytaemia, and managed as a case of septicaemia with acute kidney injury. On examination, general condition of the child was sick, pale, oedematous with abdominal distension and hepatosplenomegaly. Respiratory system examination showed features of pneumonia. Investigations were sent (Table 1). Baby was started on intravenous fluids, and injection Ceftriaxone along with nebulised salbutamol. Blood culture sent on day 2 of admission grew Pantoea spp. which was also susceptible (as above). Antibiotics were upgraded to Piperacillin + tazobactam, Linezolid and Doxycycline. Tests for enteric fever, malaria were negative. Over next two days, there was progressive dyselectrolytaemia. Fresh frozen platelets and packed red blood cells were transfused owing to worsening haemoglobin and platelet counts. On $4^{\text {th }}$ day child had a cardiac arrest and expired.

\section{Case Presentation 6}

A 7-year-old male child was admitted to the hospital with the history of bilateral swelling of cervical lymph nodes off and on for 2 years, high grade fever for 7-8 months, abdominal distension for 7-8 months and progressive pallor for 3 months. He had abdominal distension with hepatosplenomegaly, preauricular and submandibular, bilateral cervical and axillary lymphadenopathy, cardiomegaly, Sp02 94\%. Investigations done on day 1 are mentioned in Table 1. Blood culture sent on day 1 was sterile. General condition of the child was sick. He was started on intravenous fluids, injection Ceftriaxone and packed red blood cells were transfused. Histopathological examination of lymph node biopsy revealed lymphoma. The child continued to have febrile spikes and the blood culture sent on day 3 grew Pantoea spp. with same susceptibility profile as above. The antibiotics were upgraded and the fever subsided. Subsequent blood cultures were sterile.

\begin{tabular}{|c|c|c|c|c|c|c|}
\hline & Case 1 & Case 2 & Case 3 & Case 4 & Case 5 & Case 6 \\
\hline Age & 1 month & 7 years & 1 day & 6 days & 18 months & 7 years \\
\hline Gender & Male & Male & Male & Female & Male & Male \\
\hline Haemoglobin (g) & 10.7 & 6.1 & 16.4 & 19.6 & 8.9 & 3.3 \\
\hline Total Leucocyte Count (per $\mu \mathrm{L})$ & 3600 & 30200 & 36800 & 9200 & 28400 & 6400 \\
\hline Platelet counts (per $\mu \mathrm{L})$ & 95000 & 19000 & 1.28 lakhs & 3.04 lakhs & 18000 & 2.5 \\
\hline Serum urea (mg/dL) & 78.31 & 55 & - & - & 157 & 40 \\
\hline Serum creatinine (mg/dL) & 3.45 & 1.8 & - & - & 3.5 & 0.4 \\
\hline
\end{tabular}




\begin{tabular}{|c|c|c|c|c|c|c|}
\hline C-Reactive Protein (CRP in mg/L) & $\begin{array}{l}\text { Positive } \\
(20.32) \\
\end{array}$ & & - & - & $\begin{array}{l}\text { Positive } \\
(36.20) \\
\end{array}$ & - \\
\hline Serum bilirubin (total) (mg/dL) & 1.2 & 4.1 & - & 22 & 0.7 & 1.0 \\
\hline Serum bilirubin (indirect) $(\mathrm{mg} / \mathrm{dL})$ & 0.2 & 0.4 & - & 21.6 & 0.2 & 0.8 \\
\hline Alkaline phosphatase (IU/L) & 53 & 245 & - & 321 & 63 & 398 \\
\hline Serum $\mathrm{Na}^{+} / \mathrm{K}^{+}(\mathrm{mmol} / \mathrm{L})$ & $141 / 3.8$ & $130 / 6.2$ & $157 / 6.2$ & $145 / 5.1$ & $150 / 3.3$ & $138 / 0.4$ \\
\hline Serum protein $(\mathrm{g} / \mathrm{dL})$ & 4.6 & 5.2 & & 4.7 & 3.7 & 4.8 \\
\hline Serum Calcium total $(\mathrm{mmol} / \mathrm{L})$ & 9.7 & 8.0 & 10.0 & 10.1 & 7.8 & 11.3 \\
\hline Ultrasound Abdomen & $\begin{array}{c}\text { Altered } \\
\text { echotexture of } \\
\text { both kidneys, } \\
\text { distended } \\
\text { abdomen with } \\
\text { prominent } \\
\text { bowel loops }\end{array}$ & $\begin{array}{c}\text { Bilateral renal } \\
\text { raised Echo- } \\
\text { genicity with } \\
\text { inflammation } \\
\text { in perinephric } \\
\text { space, ascites, } \\
\text { coarsened liver } \\
\text { with periportal } \\
\text { cuffing. } \\
\end{array}$ & - & - & - & \begin{tabular}{|c|} 
Splenomegaly, \\
multiple discrete \\
lymph nodes \\
seen along \\
splenoportal \\
axis, mild to \\
moderate free \\
fluid in \\
abdomen \\
\end{tabular} \\
\hline
\end{tabular}

\section{DISCUSSION}

Pantoea spp. is ubiquitous in nature and its ability to grow at room temperature leads to contamination of the various articles used in patient care like cotton swabs, intra-arterial devices, intravenous solutions and stored blood products. ${ }^{4,5}$ To the best of our knowledge, outbreak due to Pantoea spp. has not been reported from our country. However, there are a few reports of neonatal infection caused by it from two places including a case of neonatal sepsis from Indore in $2013^{6}$ and a case of neonatal sepsis from Cuttack in $2015 .^{7}$

The age profile in this outbreak included a wide range of paediatric age group from neonates to 7-year-old admitted in a high dependency unit of a paediatric tertiary care hospital. All cases had comorbidities (acute kidney injury, severe anaemia, thrombocytopenia, deranged liver function tests) along with concomitant septicaemia. All these patients had fever during their stay in hospital and their blood culture samples grew Pantoea species. The isolates were morphologically identical and all were susceptible to Ceftazidime $(0.25 \mu \mathrm{g} / \mathrm{mL})$, Piperacillin + Tazobactam $(\leq 4$ $\mu \mathrm{g} / \mathrm{mL})$, Imipenem $(\leq 0.25 \mu \mathrm{g} / \mathrm{mL})$, Meropenem $(\leq 0.25$ $\mu \mathrm{g} / \mathrm{mL})$, Ciprofloxacin $(\leq 0.25 \mu \mathrm{g} / \mathrm{mL})$, Gentamicin $(\leq 1$ $\mu \mathrm{g} / \mathrm{mL})$, Amikacin $(\leq 2 \mu \mathrm{g} / \mathrm{mL})$, Trimethoprim + sulfamethoxazole $(\leq 20 \mu \mathrm{g} / \mathrm{mL})$, Colistin $(\leq 0.5 \mu \mathrm{g} / \mathrm{mL})$ and Tigecycline $(\leq 0.05 \mu \mathrm{g} / \mathrm{mL})$. There was clustering of these 6 cases within 20 days and they were from the same unit. For the initial two isolations of Pantoea spp. from patients' blood samples which occurred within the span of 3 days, there was no clue of any outbreak. It was only after the $3^{\text {rd }}$ isolate from third patient admitted to the same unit as the earlier two patients, that a possibility of outbreak was thought. By then three more patients' blood samples also had grown Pantoea spp. (also admitted to the same unit). A common environmental source in that unit was suspected and clinicians were informed of the same. Samples were collected from intravenous fluids, nebulisation fluid, normal saline used for flushing, tap water, beds, bedside tables, instrument trolley, settle plates for air from the suspected cubicle in that paediatric unit and were processed microbiologically to detect presence of Pantoea spp. However, from none of these sites Pantoea spp. could be isolated. Strengthening of infection control practices in the form of hand hygiene practices and environmental source control was done. There was no Pantoea spp. culture positive case thereafter.
P. agglomerans is intrinsically susceptible to beta-lactam antibiotics, ${ }^{8}$ which might be responsible for a localised outbreak. All cases except one succumbed to death. The study by Bicudo et $\mathrm{al}^{9}$ reported the predilection of this organism for the lungs. In this outbreak, all cases had multiorgan involvement including lung infection. Nosocomial infection can occur due to contamination from IV fluid and stored blood products. ${ }^{4,5}$ All the cases in this outbreak were sick and required IV fluid, oxygenation and ventilator support and almost everyone had to be given multiple blood product transfusions, so they were all exposed to common sources which could probably be contaminated with Pantoea spp. Though the exact source could not be identified here, our case series reports the ability of Pantoea spp. to cause outbreak.

Isolation of Pantoea spp. should not be ignored when identified from clinical samples. Also, it gives a clear indication of a breach in asepsis protocol at some end. There should be strengthening of surveillance policies by hospital infection control team to prevent such outbreaks. If such outbreaks occur, appropriate measures must be instituted timely to remove all possible exogenous sources in a hospital setting, followed by total disinfection of the environment and equipment. Most importantly, reinforcing good hand hygiene practices amongst health care providers can be a most effective and simplest measure in preventing such incidences.

\section{CONCLUSION}

Clustering of cases over a short period, points towards the ability of Pantoea spp. to cause outbreak. Reporting of Pantoea spp. should not be ignored when isolated from clinical samples. Possible exogenous sources for this organism should be monitored in a hospital setting.

\section{REFERENCES}

[1] Gavini F, Mergaert J, Beji A, et al. Transfer of Enterobacter agglomerans (Beijerinck 1988) Ewing and Fife 1972 to Pantoea gen. nov. as Pantoea agglomerans comb. nov. and description of Pantoea dispersa sp. nov. Int J Syst Bacteriol 1989;39:337-45.

[2] Liberto MC, Matera G, Puccio R, et al. Six cases of sepsis caused by Pantoea agglomerans in a teaching hospital. New Microbiol 2009;32(1):119-23. 
[3] Rostenberghe VH, Noraida R, Pauzi WIW, et al. The clinical picture of neonatal infection with Pantoea species. Jpn J Infect Dis 2006;59(2):120-1.

[4] Mackel DC, Dennis GM, Anderson RL, et al. Nationwide epidemic of septicemia caused by contaminated intravenous products: mechanism of intrinsic contamination. J Clin Microbiol 1975;2(6):486-97.

[5] Sanders WE, Sanders CC. Enterobacter spp.: pathogens poised to flourish at the turn of the century. Clin Microbiol Rev 1997;10(2):220-41.

[6] Mehar V, Yadav D, Sanghvi J, et al. Pantoea dispersa: an unusual cause of neonatal sepsis. Braz J Infect Dis 2013;17(6):726-8.
[7] Tiwari S, Beriha SS. Pantoea species causing early onset neonatal sepsis: a case report. J Med Case Rep 2015;9:188.

[8] Maki DG, Rhame FS, Mackel DC, et al. Nationwide epidemic of septicemia caused by contaminated intravenous products: epidemiological and clinical features. Am J Med 1976;60(4):471-85.

[9] Bicudo EL, Macedo VO, Carrara MA, et al. Nosocomial outbreak of Pantoea agglomerans in a pediatric urgent care center. BJID 2007;11(2):281-4. 